\title{
Activity of peroxisomal enzymes, and levels of polyamines in LPA-transgenic mice on two different diets
}

\author{
Knut A Eliassen*1, Bjørn P Brodal ${ }^{2}$, Aud Svindland ${ }^{3}$, Harald Osmundsen², \\ Helle Rønning 1 , Srdjan Djurovic ${ }^{4,5}$ and Kåre Berg ${ }^{4,5}$
}

\begin{abstract}
Address: ${ }^{1}$ Department Basic Sciences and Aquatic Medicine, Norwegian School of Veterinary Science, P.O. Box 8146 Dep. No-0033 Oslo, Norway, ${ }^{2}$ Department of Oral Biology, University of Oslo, P.O. Box 1052 Blindern, No-0316 Oslo, Norway, ${ }^{3}$ Department of Pathology, Aker University Hospital, No-0514 Oslo, Norway, ${ }^{4}$ Institute of Medical Genetics, University of Oslo, P.O. Box 1036 Blindern, Oslo, Norway and ${ }^{5}$ Department of Medical Genetics, Ullevål University Hospital, No-0407 Oslo, Norway

Email: Knut A Eliassen* - knut.eliassen@veths.no; Bjørn P Brodal - bbrodal@odont.uio.no; Aud Svindland - a.d.svindland@ioks.uio.no; Harald Osmundsen - haraldo@odont.uio.no; Helle Rønning - wkhr@weifa.no; Srdjan Djurovic - serdjan.djurovic@ioks.no;

Kåre Berg - k.berg@genova.no

* Corresponding author

Published: 04 October 2005

Lipids in Health and Disease 2005, 4:23 doi:10.1I86/I476-5IIX-4-23

This article is available from: http://www.lipidworld.com/content/4/I/23

(c) 2005 Eliassen et al; licensee BioMed Central Ltd.

This is an Open Access article distributed under the terms of the Creative Commons Attribution License (http://creativecommons.org/licenses/by/2.0), which permits unrestricted use, distribution, and reproduction in any medium, provided the original work is properly cited.

Received: 10 August 2005

Accepted: 04 October 2005
\end{abstract}

\begin{abstract}
Background: In man, elevated levels of plasma plipoprotein $(a)(\operatorname{Lp}(a))$ is a cardiovascular risk factor, and oxidized phospholipids are believed to play a role as modulators of inflammatory processes such as atherosclerosis. Polyamines are potent antioxidants and anti-inflammatory agents. It was therefore of interest to examine polyamines and their metabolism in LPA transgenic mice.
\end{abstract}

Concentration of the polyamines putrescine, spermidine and spermine as well as the activity of peroxisomal polyamine oxidase and two other peroxisomal enzymes, acyl-CoA oxidase and catalase were measured. The mice were fed either a standard diet or a diet high in fat and cholesterol (HFHC). Some of the mice in each feeding group were in addition given aminoguanidine (AG), a specific inhibitor of diamine oxidase, which catalyses degradation of putrescine, and also inhibits non-enzymatic glycosylation of protein which is implicated in the aetiology of atherosclerosis in diabetic patients. Non-transgenic mice were used as controls.

Results: Intestinal peroxisomal polyamine oxidase activity was significantly higher in LPA transgenic mice than in the non-transgenic mice, while intestinal peroxisomal catalase activity was significantly lower. Hepatic $\beta$-oxidation increased in $\operatorname{Lp}(a)$ transgenic mice fed the HFHC diet, but not in those on standard diet.

Hepatic spermidine concentration was increased in all mice fed the HFHC diet compared to those fed a standard diet, while spermine concentration was decreased. With exception of the group fed only standard diet, transgenic mice showed a lower degree of hepatic steatosis than non-transgenic mice. AG had no significant effect on hepatic steatosis.

Conclusion: The present results indicate a connection between peroxisomal enzyme activity and the presence of the human LPA gene in the murine genome. The effect may be a result of changes in oxidative processes in lipid metabolism rather than resulting from a direct effect of the LPA construct on the peroximal gene expression. 


\section{Background}

Elevated levels of plasma lipoprotein (a) Lp(a) are a significant cardiovascular risk factor in man [1]. We have earlier reported development of arteriosclerosis in aorta of mice transgenic for CDNA representing the human gene for $\operatorname{Lp}(\mathrm{a}), \mathrm{hLPA}$, on a standard diet $[2,3]$, while the nontransgenic mice only sporadically developed arteriosclerosis. In the LPA cDNA-transgenic animals, apolipoprotein(a), (apo(a)), occurs free in plasma, and we found a significant correlation between the plasma apo(a) concentration and the size of aortic lesions.

The present investigation, based on tissue samples from the animals in the above-mentioned study, was undertaken to uncover if polyamines could influence on the atherosclerotic development. There were no leftovers of blood and the aortic wall for polyamine measurements. The liver and kidney were therefore chosen.

The rationale for examining the polyamines, spermidine and spermine, is that their positive charges strongly interact with phospholipids and inhibit lipid peroxidation [4], and to a certain extent protect liposome from oxidation [5]. In addition, spermine exhibits an anti-inflammatory effect [5] and exerts an antagonistic action on platelet aggregation [6]. Since cell proliferation in the vascular walls is important in the development of atherosclerotic lesions, knowledge of levels and metabolism of polyamines are per se of interest because of their wellknown importance for cell growth and differentiation. In addition it was of interest to measure the activity of the peroxisomal polyamine oxidase, an enzyme important in converting polyamines [7]. Examination of the activity of peroxisomal enzymes was of interest also because the peroxisomal proliferators activated receptors (PPARs) are known to be involved in the development of arteriosclerosis (for review, see [8]. We have earlier shown that feeding rats a diet enriched in polyamines resulted in a decrease in hepatic polyamine oxidase and catalase activity, which could be restored by simultaneously supplementing the diet with clofibrate, a peroxisomal proliferator and a hypolipidemic drug [9].

The fact that the hypolipidemic drug, clofibrate, changed the activity of polyamine oxidase indicates that the fat content of tissues may influence polyamine metabolism. It was therefore of special interest to examine if fat loading had any effect on liver polyamine content, and on polyamine oxidase activity.

In the present study we found that polyamine oxidase activity was higher in transgenic mice than in non-transgenic animals. In order to examine whether this reflects a general increase in peroxisomal enzymes, we measured the activity of two other peroxisomal enzymes, catalase and $\beta$-oxidase. Catalase decomposes $\mathrm{H}_{2} \mathrm{O}_{2}$, a product of oxidase activity, and thereby protects the cell against the toxic effect of $\mathrm{H}_{2} \mathrm{O}_{2}$, while peroxisomal $\beta$-oxidation plays the important physiological role of oxidation very long fatty acids and the side chain of cholesterol.

Some groups of mice were treated with AG because AG inhibits the formation of non-enzymatic glycosylation of proteins [10], which are implicated in the aetiology of diabetic complications, including arteriosclerosis [10,11], and because AG is a well-known specific inhibitor of diamine oxidase, which catalyses degradation of putrescine, the precursor of the polyamines; spermidine and spermine.

We here report that the introduction of the human LPA gene into FVB mouse resulted in no significant changes in the polyamine concentration in liver and kidneys, but it changed the activity of three peroxisomale enzymes namely: intestinal polyaminoxidase and catalase and hepatic acyl-CoA oxidase (responsible for $\beta$-oxidation). There seemed to be less hepatic steatosis in the transgenic mice compared to the control FVB mice.

In mice fed a HFHC diet compared to those fed a standard low fat diet, the hepatic spermidine and spermine concentrations were different, resulting in a lower ratio between spermidine and spermine concentrations in the HFHC fed mice.

\section{Results}

The results did not suggest a sex difference with respect to any of the measured parameters.

\section{Body weight}

Body-weight decreased by $2-5 \%$ during the experimental period. Animals treated with aminoguanidine showed the highest weight-loss. The reduction in the body weight may be related to the relatively high age of the mice. Mice on the high fat diet, showed an intermittent increase in body weight of $2-9 \%$, with a peak about 3 weeks after start. However, mean body weight at the end of the treatment period, was not significantly different from those of the groups fed a standard diet (data not shown).

\section{Polyamine oxidase activity}

The small intestinal polyaminoxidase activity was significantly $(\mathrm{p}<0.05)$ higher in the transgenic mouse groups than in the non-transgenic. The polyamine oxidase activity in the small intestine was about twice as high as in the liver. Data showing the effects of the treatments on intestinal polyamine oxidase activity are presented in Fig 1. Hepatic polyamine oxidase activity was $0.41 \pm 0.06 \mathrm{nmol} /$ $\mathrm{min} \cdot \mathrm{mg}$ and was not affected by the diet fat content, $\mathrm{AG}$ treatment, or transgenity. 


\section{Intestinal polyamine oxidase activity}

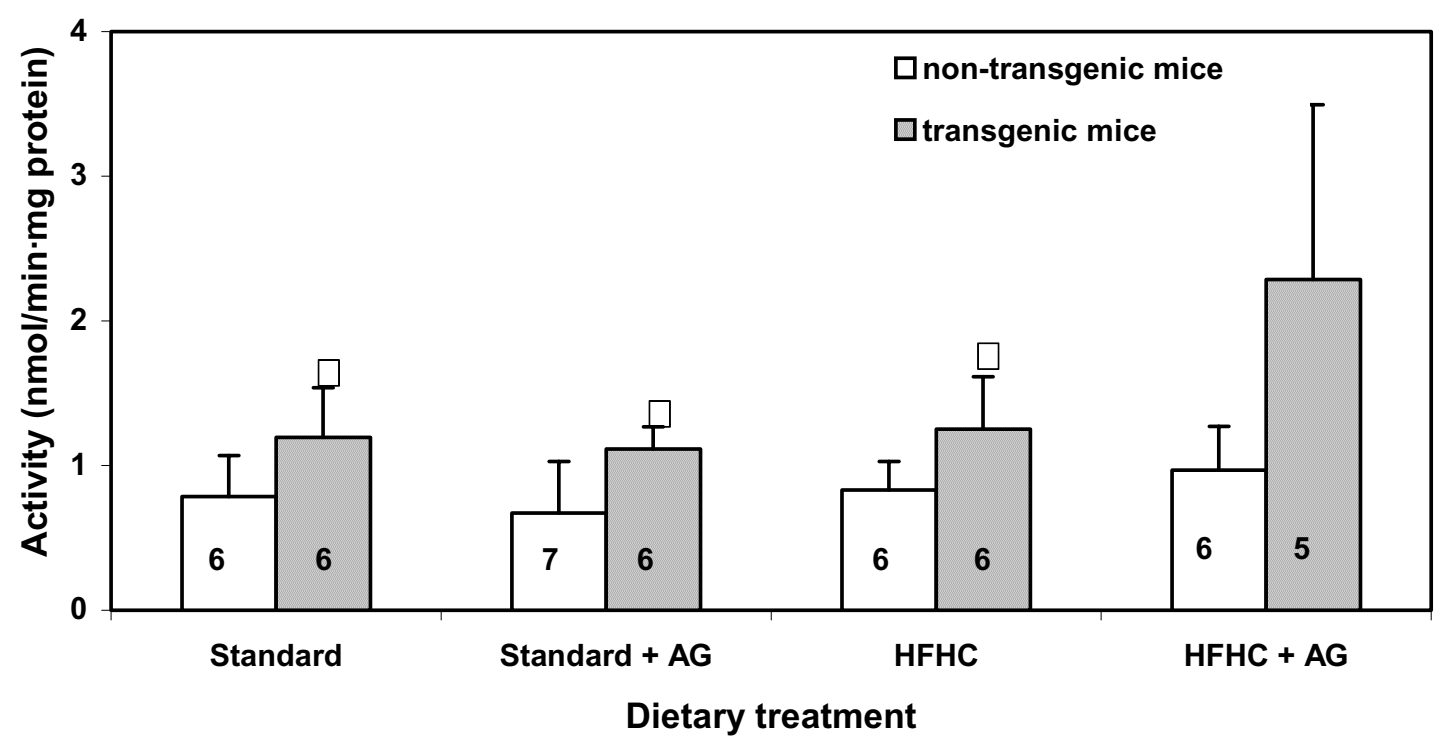

Figure I

Intestinal polyamine oxidase activity in LPA transgenic and non-transgenic mice. The mice were fed two different diets, one high in fat and cholesterol (HFHC diet), the other a standard diet low in fat. Some of the animals from each group (see Table I) were treated with $0.5 \%$ AG (aminiguanidine) in the drinking water. After 100 days of treatment the activity of the enzyme was assayed. The number of mice in each group is given with numbers within each column. Experimental details are given in Materials and Methods. The histograms represent means with SD indicated. Population means that were significantly different from the non-transgenic mice are denoted with asterisk, $*(p<0.05)$.

\section{Catalase activity}

Figure 2 shows the catalase activity measured in homogenates from the small intestine. In all treatment groups the catalase activity in the transgenic animals was significant lower than in the non-transgenic mice. In transgenic mice, given aminoguanidine in the drinking water, the catalase activity was significantly higher in those on the HFHC diet than in those on the standard diet (Fig. 2). AG treatment of transgenic mice on the standard diet reduced the intestinal catalase activity significantly.

There were only minor and insignificant differences in hepatic catalase activity between transgenic and nontransgenic mice and between the two diets. The activity was roughly the same as in the small intestine of nontransgenic mice.

AG in the drinking water to mice on the HFHC diet resulted in an increased hepatic catalase activity from about 1.5 to $3.0 \mu \mathrm{mol} \mathrm{H}_{2} \mathrm{O}_{2} / \mathrm{s} \cdot \mathrm{mg}$ protein.

\section{Peroxisomal $\beta$-oxidation (hepatic acyl-CoA oxidase activity)}

Peroxisomal $\beta$-oxidation in livers of transgenic mice fed the HFHC diet and aminoguanidine in the drinking water was significantly $(\mathrm{p}<0.05)$ higher than in the non-transgenic mice on the same treatment (Fig. 3). In corresponding experiment with mice on the same diet, but without 


\section{Intestinal catalase activity}

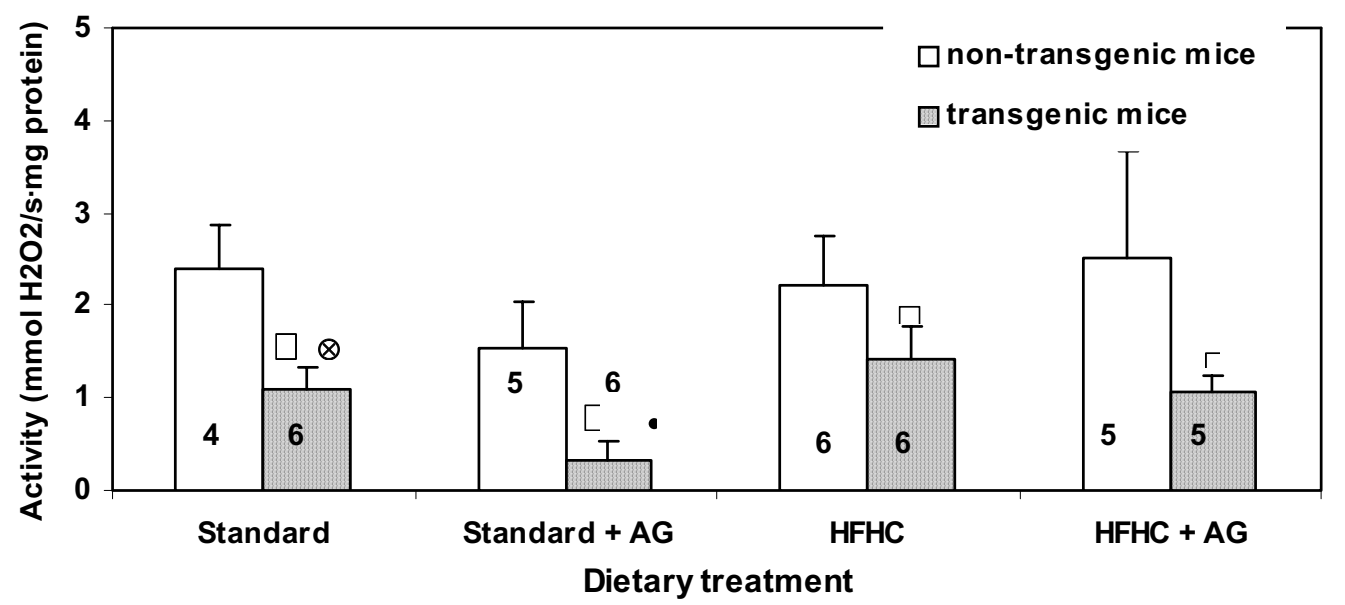

\section{Figure 2}

Intestinal catalase activity in LPA transgenic and non-transgenic mice. The histograms represent means with SD indicated. Population means that were significantly different from the non-transgenic mice $(p<0.05)$ are denoted with *. Population means denoted with $\bullet$ indicate difference from the corresponding mice fed the HFHC diet and $\otimes$ indicate significant differences from the corresponding aminoguanidine (AG) treated mice. Experimental details are given in the legend to Fig. I and in Materials and Methods section.

aminoguanidine (Fig. 3), the difference observed did not reach statistical significance.

\section{Intestinal diamine oxidase activity}

The diamine oxidase activity in the proximal part of the small intestine was powerfully inhibited in animals given $A G$, irrespective of their genetic status. The mean \pm SD values of diamine oxidase activity expressed as amount putrescine turnover pr. min and g tissue was $220 \pm 160$ and $17200 \pm 6200$ pmol for the aminoguanidine treated and the non-treated animals, respectively. This is in agreement with the established inhibitory effect of aminoguanidine on diamine oxidase activity [12].

\section{Tissue polyamines}

The hepatic concentrations of putrescine wearied around the level of detection of the assay. Evaluation of these data could therefore not be carried out.

With exception of mice on standard diet and aminoguanidine treatment, transgenic and non-transgenic mice exhibited no significant differences in hepatic spermidine and spermine concentrations (Figs. 4 and 5)
The hepatic concentration of spermidine in mice fed the atherogenic diet, HFHC; was significantly $(\mathrm{p}<0.05)$ lower than in mice given standard diet (Fig. 4). On the other hand, a slight, but significant increase $(\mathrm{p}<0.05)$ in spermine concentration was observed in mice fed the HFHC diet without AG in the drinking water, compared to those fed the standard diet (Fig. 5). The spermidine/spermine ratio was 0.76 for mice on the HFHC diet, and 1.32 for those on standard diet.

In kidney there were no differences between transgenic and non-transgenic mice. Thus for the non-transgenic mice the putrescine, spermidine and spermine concentrations were $(73 \pm 36) \mathrm{nmol} / \mathrm{g}$, $(363 \pm 83) \mathrm{nmol} / \mathrm{g}$ and $(606$ $\pm 101) \mathrm{nmol} / \mathrm{g}$, respectively, and the corresponding values for the transgenic animals were $66 \pm 22,398 \pm 170$ and $642 \pm 154 \mathrm{nmol} / \mathrm{g}$. Furthermore, there was no difference between mice on the two diets, or between AG treated and untreated mice.

\section{Hepatic steatosis}

In the fatty infiltrations, there was no sign of inflammatory cells. Hepatic steatosis was graded from 1 to 3 . 


\section{Hepatic peroxisomal ß-oxidation}

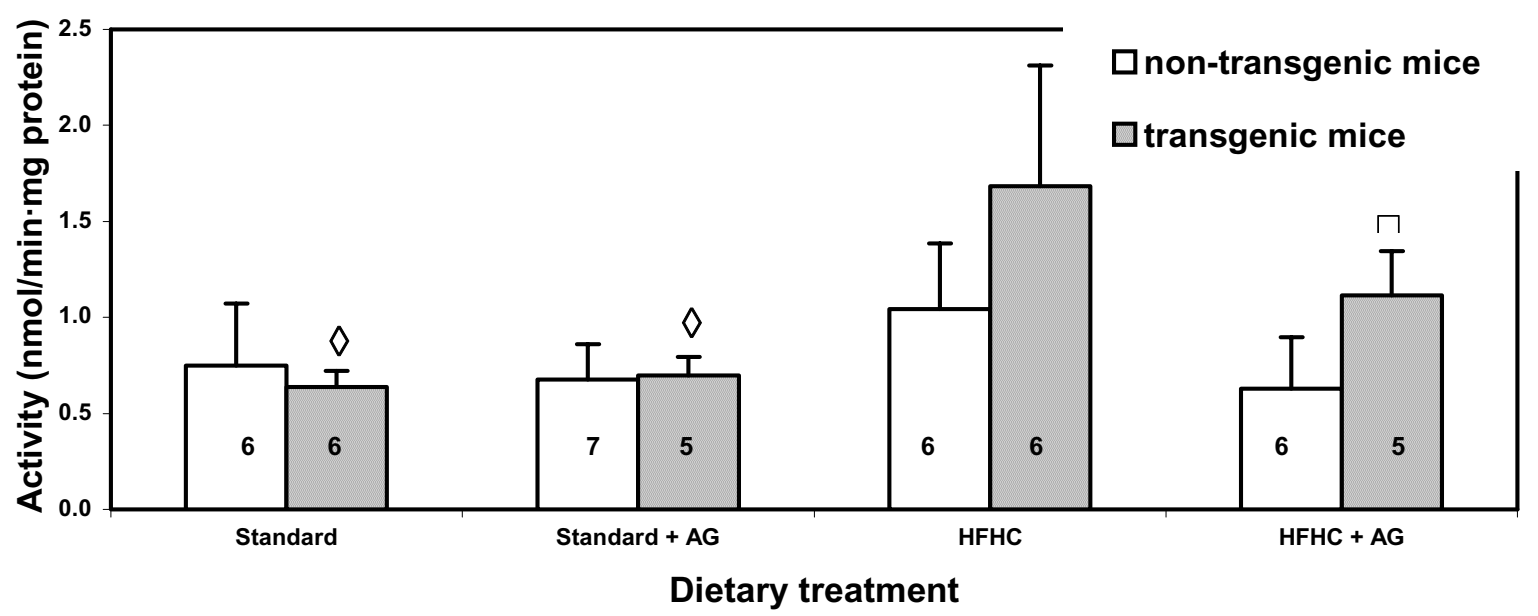

Figure 3

Hepatic peroxisomal $\beta$-oxidation activity in LPA transgenic mice and non-transgenic mice. Experimental details are given in the legend to Fig. I and in Materials and Methods section. The histograms represent means with SD indicated. Population means that were significantly different $(p<0.05)$ from non-transgenic mice are denoted with *. Population means denoted with indicate significant differentce from the corresponding mice fed a HFHC diet.

Typical sections of liver with steatosis of grade 1, 2 and 3, together with sections of a normal liver are shown in Fig. 6. Steatosis occurred in the liver of all, but four mice. The grade of steatosis was lower in the transgenic mice than in non-transgenic mice, but the difference was statistical significant $(\mathrm{p}<0.05)$ only for those on a standard diet with AG in the drinking water and for those fed only a high fat diet (Fig. 7).

\section{Discussion \\ Enzyme activities}

Introduction of cDNA representing the LPA gene together with the transferrin promotor, into the mouse genome resulted in changes in activity of the peroxisomale enzymes polyamine oxidase and catalase in the small intestine, but not in the liver (Figs. 2, 3, 4). This is in contrast to the fact that the LPA gene is expressed in liver, but not in the intestines [13], indicating that the effect on the intestinal enzymes must be secondary. Since the genes coding for polyamine oxidase (Locus ID no Mm 212503) and for acyl-CoA oxidase (Locus ID no. Mm 11430) are located on different mouse chromosomes, 7 and 11 , respectively, it is unlikely that the observed changes in these enzyme activities were caused by the introduction of the LPA gene with a transferrin promotor, in or near the regulator region of the gene for these enzymes.

The increased intestinal polyamine oxidase activity in LPA transgenic mice compared to non-transgenic mice (Fig. 1), indicates an altered peroxisomal polyamine metabolism. When the activity of the $\mathrm{H}_{2} \mathrm{O}_{2}$ producing polyamine oxidase enzyme is increased in the transgenic mice, an increase in the catalase activity should be anticipated. However, the opposite was the case.(Fig. 2) Increased polyamine oxidase activity can therefore not be explained by a general increase in activity of peroxisomal enzymes. The increase in $\mathrm{H}_{2} \mathrm{O}_{2}$ production from enhanced polyamine oxidase activity is probably marginal, compared with $\mathrm{H}_{2} \mathrm{O}_{2}$ production from other sources. The observed changes in hepatic peroxisomal $\beta$-oxidation (Fig. 3) cannot explain the decrease in the catalase activity because peroxisomal $\beta$-oxidation did not change in the control mice and even increased in the LPA-transgenic mice on HFHC diet. The increased peroxisomal $\beta$-oxida- 


\section{Hepatic spermidine}

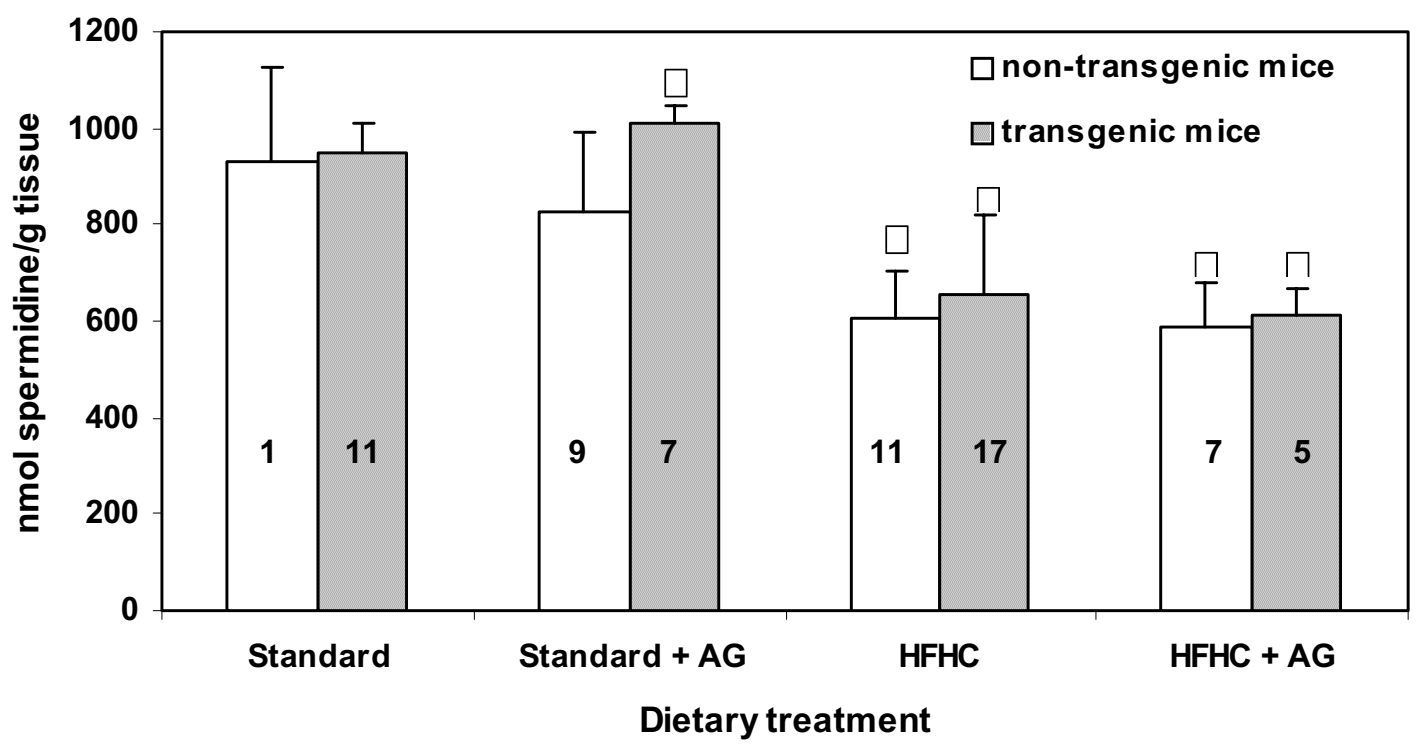

Figure 4

Hepatic spermidine concentration in LPA transgenic and non-transgenic mice. The columns represent means with SD indicated. Population mean that is significantly different from that of non-transgenic mice is denoted with asterisk, *. $\Delta$ Indicate significant difference from the corresponding groups fed a standard diet. Experimental details are given in the legend to Fig I and in the Materials and Methods section.

tion in LPA transgenic mice on the HFHC diet is in agreement with reports showing that diets high in fat, particular those containing hydrogenated fat, cause increased of peroxisomal $\beta$-oxidation $[14,15]$. In non-transgenic mice the same diet caused no significant increase of peroxisomal $\beta$ oxidation. It follows that mice, transgenic with respect to LPA may be more prone than non-transgenic mice to increase of peroxisomal $\beta$-oxidation probably because of the low fat content (Fig. 2).

The observed increase in polyamine oxidase and $\beta$-oxidase activity together with a decrease in catalase activity indicate that also other oxidative processes are changed as a result of the introduction of the LPA gene. This seems interesting in the view of the possible role of oxidized phospholipids as modulators of inflammatory processes. Thus, modified phospholipids accumulate at sites of inflammation such as atherosclerotic lesions [16]. Fur- thermore, oxidized phospholipids are shown to induce expression of atherosclerosis-related genes [17]. Additional evidence has been provided by the use of murine natural monoclonal IgM antibody, EO6, which binds to oxidation-specific epitopes on oxidized low-density lipoprotein. A high correlation between plasma $\operatorname{Lp}(\mathrm{a})$ and EO6 was then found [18].

The conclusion so far must be that changes in the three peroxisomal enzyme activities in LPA-transgenic mice is more likely to be caused by altered lipid metabolism in these animals, rather than by a direct effect of the LPA construction on the expression of the peroxisomal genes.

\section{Polyamines}

In the kidneys, neither the LPA gene nor the HFHC diet and AG treatment seemed to influence the polyamine levels significantly (data not shown). 


\section{He patic spermine}

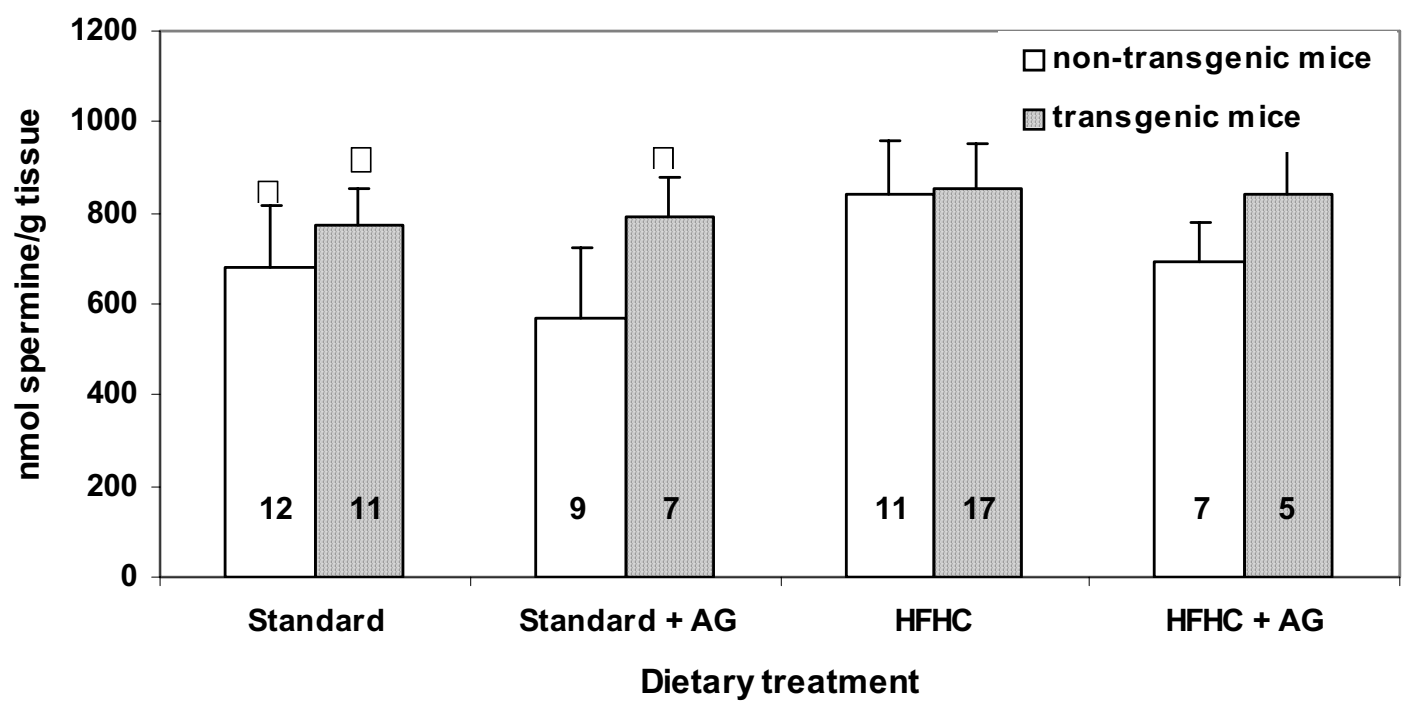

\section{Figure 5}

Hepatic spermine concentration in LPA transgenic and non-transgenic mice. The columns represent means with SD indicated. Population mean that is significantly different $(p<0.05)$ from that of the non-transgenic mice is denoted with asterisk, $* . \Delta$ Indicate significant difference $(p<0.05)$ from the corresponding HFHC fed groups. Experimental details are given in the legend to Fig. $I$ and in the Materials and Methods section.

The hepatic spermidine and spermine concentration were almost unaffected by aminoguanidine treatment (Fig. 4 and 5). The same was true for the kidneys. Although the polyamine concentration in the standard diet was much higher than in the HFHC diet, the HFHC diet resulted in higher hepatic spermidine concentration. It seems not likely that differences in the intestinal micro flora caused the observed differences in hepatic polyamine content between the two feeding groups.

Clofibrate treatment, that decreases plasma lipid levels has earlier been found to increase the hepatic content of spermidine and reduce that of spermine [9], which is contrary to the effect of the HFHC diet.

The HFHC fed group had higher levels of hepatic fat, as judged by the amount of fat filled vacuoles (steatosis) than those on the standard diet. However, we found no significant correlation between hepatic steatosis and hepatic levels of spermidine or spermine. In spite of that, we suggest that hepatic lipid level may be of importance for the hepatic polyamine level. The fact that spermine binds to negatively charged lipids, e.g. phospholipids [19] may in part explain the increased spermine concentration in liver.

Spermidine in plasma can bind to HDL [20], which is known to inhibit the formation of oxidized low-density lipoprotein (LDL) [21]. Polyamines, especially spermine, are also potent antioxidants and anti-inflammatory agents [5]. The polyamine concentrations have further been reported to inhibit platelet aggregation in hypercholesterolemic rabbits [6]. Studies of the role of polyamines in atherogenesis/thrombogenesis are therefore called for.

The spermidine/spermine ratio is known to be high in fast growing tissue. Thus, in rat liver at birth the ratio is 4.5 , whereas this ratio at 9 months is 0.8 [22]. One can only speculate if the cell turnover rate for liver cells in mice fed the HFHC diet, that have a hepatic spermidine/spermine 
A

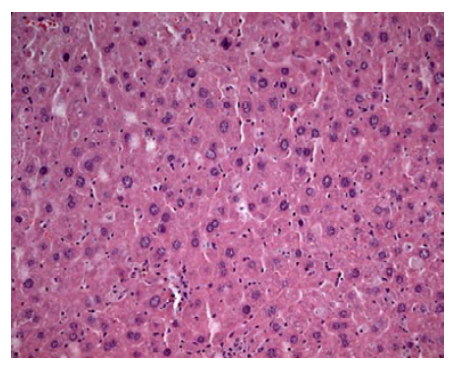

B

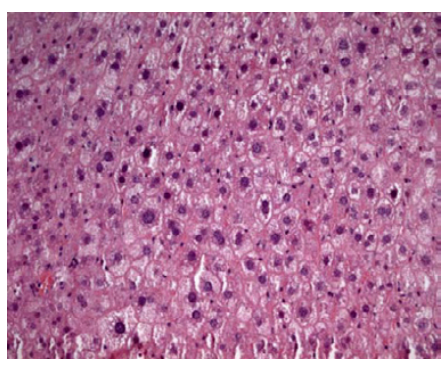

C

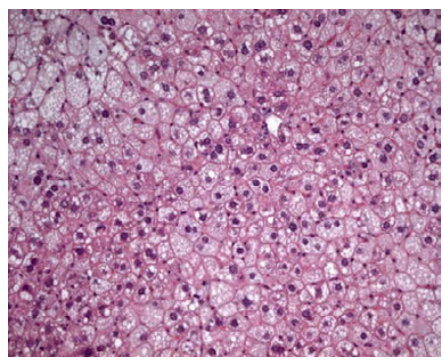

D

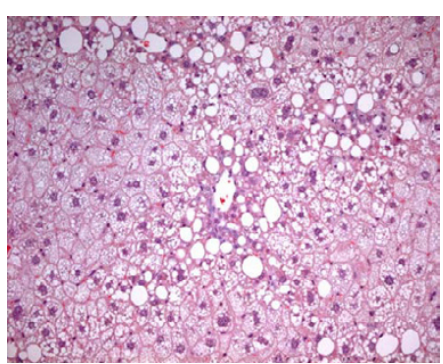

\section{Figure 6}

Scoring of hepatic steatosis. A) Normal liver with no lipid deposits, grade 0, B) Liver tissue with steatosis grade I (slight steatosis), C) grade 2, that between slight and serve stearosis, D) Liver tissue with steatosis grade 3 (serve steatisis), almost all cells are affected and many with large fat vacuoles. Magnification 1000x. ratio on 0.76 , is reduced compared to that of mice on a standard diet where the corresponding ratio was 1.32 .

\section{Liver steatosis}

For two of the feeding groups there was significantly lower degree of hepatic steatosis in the transgenic mice than in the non-transgenic animals (Fig 7) suggesting differences in lipid metabolism. We have earlier reported a significantly higher rate of aortic lesions in LPA transgenic mice than in non-transgenic animals and a positive correlation between apo(a) level and size of aortic lesions [2,3]. This, together with the fact that inflammatory cells only could be seen in the aortic fat infiltrations, not in that of the liver, indicate that there are different mechanisms involved in the deposition of lipids in aortic lesions and in liver cells.

The AG treated mice on the HFHC diet had less steatosis than the untreated animals but the differences were far from significant. This indicates that glycosylation is not participating in the formation of hepatic steatosis in mice.

\section{Conclusion}

An increase in polyamine oxidase activity in hLPA transgenic mice, and an increase in $\beta$-oxidation in transgenic mice fed a HFHC diet, together with a decrease in catalase activity may indicate that also other oxidative processes are changed as a result of the introduction of the LPA gene. Such changes would be of great interest because oxidation products are known to be important in the development of arteriosclerosis.

Changes in the polyamine pattern upon increased fat intake are also noteworthy. However, in this study we have not been able to show any connection between polyamines/polyamine-metabolism and the arteriosclerotic lesion seen in the same mice $[2,3]$. Further studies are warranted.

\section{Materials and methods \\ Reagents}

Horseradish peroxidase (EC 1. 11. 1. 7) (Type VI. RZ between 250 and $330 \mathrm{U} / \mathrm{mg}$ ), N1-acetyl-spermine, 4-aminoantipyrine, palmitoyl-CoA, NAD ${ }^{+}$, FAD, HEPES, hexanediamine, putrescine $2 \mathrm{HCl}$, spermidine $3 \mathrm{HCl}$, spermine $4 \mathrm{HCl}$, and mannitol were purchased from Sigma Chemical Co. (St. Louis, MO., USA). Perhydrol $\left(\mathrm{H}_{2} \mathrm{O}_{2}\right)$ was obtained from E. Merck (Darmstadt, Germany). All other reagents were of analytical grade. $\left[1,4-{ }^{14} \mathrm{C}\right]$-Putrescine dihydrochloride (spes.act. $2.11 \mathrm{GBq} / \mathrm{mmol}$ ) was obtained from Amersham Pharmacia Biotech, Ltd. (Rainham, Essex, UK). 


\section{Hepatic steatosis}

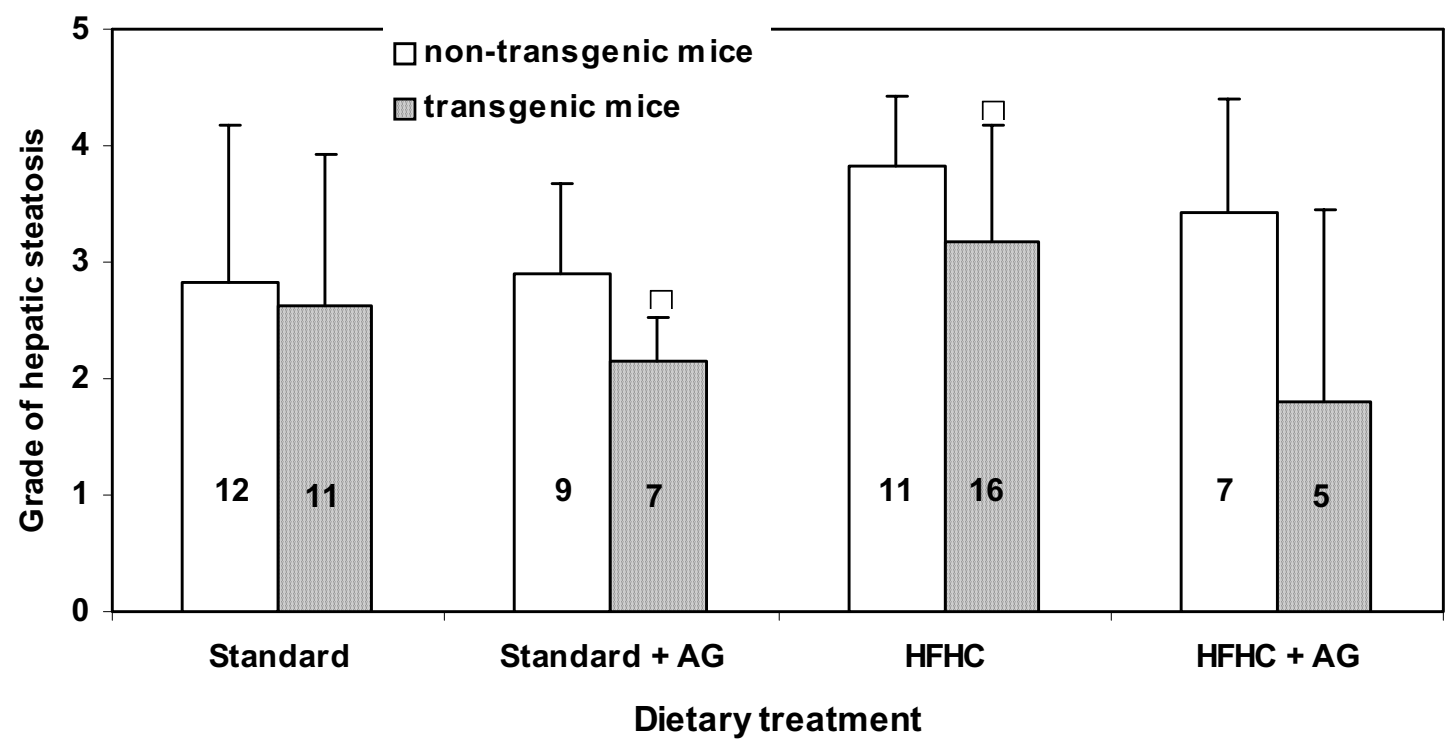

\section{Figure 7}

Hepatic steatosis (grade 0 to 3 ) in LPA transgenic and non-transgenic mice. The columns represent means with SD indicated. Population means that are significantly $(p<0.05)$ different from the non-transgenic mice are denoted with asterisks, *. Experimental details are given in the legend to Fig. I and in the Materials and Methods section.

\section{Animals and feeding}

This stock of mice have also been used in a parallel investigation of effects of the LPA gene on the development of aortic lesions $[2,3]$. Forty-one transgenic mice with cDNA representing the human LPA gene linked to the mouse transferrin promotor were studied. The mice were of a hybrid genetic background of strain C57BL/ 6 crossed with strain SJL $[2,3]$. The original transgenic breeder mice were a generous gift from Dr. Richard M. Lawn, Falk Cardiovascular Research Center, Stanford University, CA., USA. Twenty-nine non-transgenic littermates from breeding between transgenic and non-transgenic mice were used as controls. DNA analyses of white blood cells were performed to ascertain the LPA transgenic status of the mice. The mice were of both sexes and between 49 and 67 weeks of age when the study started (see Table 1).

Half of the animals were fed a standard mouse diet (RMI (E) SQS, Special Diets Services, Witham, Essex, England) containing $2.6 \%$ fat (crude oil), where saturated fat accounted for $20 \%$. The other half of the animals, were fed an atherogenic semi-purified diet high in fat and cho- lesterol (HFHC diet), containing $1.25 \%$ cholesterol, $18.4 \%$ regular butter and $0.5 \%$ sodium cholate (ICN Pharmaceuticals, Inc. 1731 Asse-Relegem, Belgium). Several of the animals on each diet were given $0.1 \%(\mathrm{w} / \mathrm{v})$ aminoguanidine in the drinking water (Table 1). All the treatments lasted for 100 days.

The amounts of polyamines in the standard diet were: 110 $\mathrm{nmol} / \mathrm{g}$ putrescine, $240 \mathrm{nmol} / \mathrm{g}$ spermidine and $45 \mathrm{nmol} /$ $\mathrm{g}$ spermine. The corresponding figures for putrescine and spermidine in the HFHC diet were 1.0 and $3.5 \mathrm{nmol} / \mathrm{g}$, respectively. Spermine could not be detected.

Females and males were housed separately, with 1-5 mice per cage. They had a $12 \mathrm{hrs}$. light/dark cycle, a constant temperature of $21^{\circ} \mathrm{C}$ and a relative humidity of $65 \%$. Sentinel mice were used to run a FELASA-style health-monitoring scheme. The mice were clinically healthy throughout the experimental period. The mice were raised in The Laboratory Animal Unit at Norwegian School of Veterinary Science (accredited by the Association for Assessment and Accreditation of Laboratory Animal Care 
Table I: Diet, treatments, age and sex distribution of LPA transgenic and non-transgenic mice

\begin{tabular}{|c|c|c|c|c|c|c|}
\hline \multirow[b]{2}{*}{ Diet and treatment } & \multicolumn{3}{|c|}{ Non-transgenic mice } & \multicolumn{3}{|c|}{ Transgenic mice } \\
\hline & No. & Sex & $\begin{array}{l}\text { Age (days), } \\
\text { mean } \pm \text { SD }\end{array}$ & No. & Sex & $\begin{array}{l}\text { Age (days), } \\
\text { mean } \pm \text { SD }\end{array}$ \\
\hline Standard & 12 & F $6, M 6$ & $481 \pm 46$ & 11 & $\mathrm{~F} 4, \mathrm{M} 7$ & $469 \pm 36$ \\
\hline Standard + aminoguanidine & 9 & F 5, M 4 & $501 \pm 55$ & 7 & $\mathrm{~F} 3, \mathrm{M} 4$ & $498 \pm 53$ \\
\hline HFHC & 11 & F 8, M 3 & $467 \pm 16$ & 17 & $F 8, M 9$ & $486 \pm 42$ \\
\hline HFHC + aminoguanidine & 7 & F 5, M 2 & $498 \pm 51$ & 5 & F 2, M 3 & $476 \pm 20$ \\
\hline
\end{tabular}

$F=$ females

$M=$ males

and Use International, Brussels, Belgium), and they were kept according to the regulations of the Norwegian Gene Technology Act of 1994. The study was approved by the Norwegian Animal Research Authority.

\section{Blood sampling and preparation of tissue samples for enzyme measurements}

The mice were anaesthetized by a subcutaneous injection of $0.05 \mathrm{ml} / 10 \mathrm{~g}$ body-weight of a 1:1 mixture of Fenatyl/ Midazolum (Hypnorm "Janssen" diluted 10x with water and Dormicum "Roche" $5 \mathrm{mg} / \mathrm{ml}$ ) prior to blood sampling, which was done by an incision in vena saphena. The mice were afterwards killed by neck dislocation, and tissues for analysis were removed as quickly as possible. After removal, the liver was weighed, and transferred into ice-cold mannitol-medium (300 mmol/L mannitol, 25 $\mathrm{mmol} / \mathrm{L}$ HEPES, $1 \mathrm{mmol} / \mathrm{L}$ EGTA, pH 7.2). A 10\% (w/v) homogenate was prepared by 2 strokes in a Potter-Elvehjem homogenizer equipped with a Teflon ${ }^{\circledR}$ piston. The homogenate was centrifuged for $1 \mathrm{~min}$ at $1075 \times \mathrm{g}_{\mathrm{av}}$. The resulting supernatants were transferred into several small vials, and stored at $-20^{\circ} \mathrm{C}$ until analyzed.

A $20 \mathrm{~cm}$ long proximal segment of the small intestine, starting about $0.5 \mathrm{~cm}$ from the pyloric sphincter, was prepared. It was cut open longitudinally, rinsed with ice-cold $0.9 \%(\mathrm{w} / \mathrm{v}) \mathrm{NaCl}$, blotted against filter paper, and homogenized for $15 \mathrm{~s}$ in ice-cold mannitol medium with an Ultra-Turrax $^{\circledast}$ at $25,000 \mathrm{rpm}$. The resulting homogenate was subsequently centrifuged at $1075 \times \mathrm{g}_{\mathrm{av}}$ for $15 \mathrm{~min}$ and the supernatant was stored at $-20^{\circ} \mathrm{C}$ until it was analyzed. Prior to assays, one part of the homogenate was mixed with one part of ice-cold mannitol medium, and then Triton $\mathrm{X}-100$ was added to a resulting concentration of $0.05 \%(\mathrm{v} / \mathrm{v})$.

\section{Enzyme assays}

Catalase (EC 1.11.1.6) activity was assayed by monitoring the decomposition of $\mathrm{H}_{2} \mathrm{O}_{2}$ at $240 \mathrm{~nm}$ and $25^{\circ} \mathrm{C}$ essentially as described by Bergmeyer et al [23]. Catalase is labile in dilute solution. Therefore, homogenates were diluted 10 times with $20 \mathrm{mmol} / \mathrm{L}$ potassium phosphate buffer, pH 7.4 immediately prior to analysis.

Peroxisomal $\beta$-oxidation was assayed as palmitoyl-CoAdependent $\mathrm{NAD}^{+}$-reduction, according to Hovik and Osmundsen [24]. Polyamine oxidase (polyamine: oxygen oxidoreductase, EC 1.5.3.3) was assayed spectrophotometrically as described by Hayashi et al. [25]. Diamine oxidase, EC 1.4.3.6 was determined radiometrically, as described by Okuyama and Kobayashi [26].

Catalase activity, peroxisomal $\beta$-oxidation and polyamine oxidase activity were measured in 6 randomly selected mice from each of 7 groups of animals, whereas all 5 mice in the transgenic group on HFHC diet and AG were examined. As seen in Fig. 3 the numbers of mice in some other groups were also less than 6 , due to accidental loss of some samples.

\section{Polyamine assays}

Tissue specimens were weighed and thereafter homogenized in 4 volumes of 5\% trichloroacetic acid. Hexane diamine was added as an internal standard. The homogenates were kept on ice for $1 \mathrm{hr}$, followed by centrifugation at $2{ }^{\circ} \mathrm{C}$ for $10 \mathrm{~min}$ at $5000 \mathrm{~g}_{\mathrm{av}}$. The supernatant was stored at $-20^{\circ} \mathrm{C}$ until analyzed. The polyamines were dansylated $[27,28]$ and separated by HPLC [29] on a Radial PAK-A column (Waters, Milford, Ma., USA).

\section{Assay of proteins}

Protein assay were carried out using the biuret method [30] with Boehringer Precimat (Boehringer Mannheim, Mannheim, Germany) as protein standard.

\section{Liver steatosis}

Liver tissue for morphometric studies were removed and immediately placed in a buffered formaldehyde solution. The examination was made routinely on sections of liver, in paraffin blocks, stained with Oil red $\mathrm{O}$ and counterstained with hematoxylin. Hepatic steatosis was identified by light microscopy as empty vacuoles in the cytoplasm of 
liver cells (Fig. 7). For definitive identification of lipid, frozen sections from separate specimens were stained with Oil Red O. The same pathologist examined the sections blindly, and all measurements were performed four times. The evaluation of visible fat in the liver cells was assessed using a semi quantitative scale from 0 to 3 . Zero indicates that no vacuolated liver cells could be detected. In the slightest degree of steatosis (grade 1) tiny vacuoles are found in small parts of the lobule, whereas in the severe case (grade 3 ) almost every liver cell is affected and most cells have large vacuoles. "Moderate" (grade 2) denotes fatty changes between that of slight and severe steatosis (Fig. 7).

\section{Statistical analysis}

To calculate the significance of differences between nontransgenic and transgenic mice on the same treatment we used an unpaired, two tailed t-test, employing the GraphPad Prism v.2.0 program (GraphPad software Inc., San Diego, USA).

The values given in the text and legends to Figures are means, with SD as indicated.

\section{List of abbreviations}

AGE, advanced glycosoationtion end products; AG, aminoguanidine; HFHC, diet high in fat and cholesterol; LPA, gene encoding apo(a).

\section{Authors' contributions}

SD was responsible for the testing of transgenicity of animals used in this study. BPB and $\mathrm{HO}$ were responsible for measurements of $\beta$-oxidation, polyamine oxidase and catalase activity. AS did the pathological examinations. HR measured the polyamines. $\mathrm{KB}$ and $\mathrm{KAE}$ conceived the study and performed its design and coordination. KAE drafted the manuscript. All authors read and approved the final version of the manuscript.

\section{Acknowledgements}

We gratefully thank Dr. Richard M. Lawn for the generous gift of LPA transgenic mice. The skillful technical assistance of Patrica A. Engen, Bente B. Gehrken, Tove Norén, Inger E. Nossen and Toril Woldene is highly appreciated.

\section{References}

I. Djurovic S, Berg K: Epidemiology of Lp(a) lipoprotein: its role in atherosclerotic/thrombotic disease. Clinical Genetics 1997, 52:28I-292.

2. Svindland A, Berg K, Eliassen K, Lawn RM, Djurovic S, Alestrom P, Noren T, Smith A: Histopathology of arterial lesions in LPA transgenic mice on cholesterol-enriched chow. Atherosclerosis 2000, I 53:349-354.

3. Berg K, Svindland A, Smith AJ, Lawn RM, Djurovic S, Alestrom A, Alestrom $P$, Eliassen $K$ : Spontaneous atherosclerosis in the proximal aorta of LPA transgenic mice on a normal diet. Atherosclerosis 2002, 163:99-104.

4. Tadolini B, Cabrini L, Landi L, Varani E, Pasquali P: Polyamine binding to phospholipid-vesicles and inhibition of lipid-peroxida- tion. Biochemical and Biophysical Research Communications 1984, I 22:550-555.

5. Lovaas E, Carlin G: Spermine - an antioxidant and anti inflammatory agent. Free Radical Biology and Medicine I99I, I I:455-46I.

6. de la Pena HC, Sosa-Melgarejo JA, Ramos RR, Mendez JD: Inhibition of platelet aggregation by putrescine, spermidine, and spermine in hypercholesterolemic rabbits. Archives of Medical Research 2000, 31:546-550.

7. Seiler N, Bolkenius FN, Rennert OM: Interconversion, catabolism and elimination of the polyamines. Medical Biology 1981, 59:334-346.

8. Duval C, Chinetti G, Trottein F, Fruchart JC, Staels B: The role of PPARs in atherosclerosis. Trends in Molecular Medicine 2002, 8:422-430.

9. Brodal BP, Eliassen KA, Ronning H, Osmundsen H: Effects of dietary polyamines and clofibrate on metabolism of polyamines in the rat. Journal of Nutritional Biochemistry 1999, 10:700-708.

10. Brownlee M, Vlassara H, Kooney A, Ulrich P, Cerami A: Aminoguanidine prevents diabetes-induced arterial-wall protein crosslinking. Science 1986, 232:1629-1632.

II. Li YM, Steffes M, Donnelly T, Liu C, Fuh H, Basgen J, Bucala R, Vlassara $H$ : Prevention of cardiovascular and renal pathology of aging by the advanced glycation inhibitor aminoguanidine. Proceedings of the National Academy of Sciences of the United States of America 1996, 93:3902-3907.

12. Schayer RW, Kennedy J, Smiley RL: Studies on histamine-metabolizing enzymes in intact animals II. Journal of Biological Chemistry 1953, 205:739-748.

13. Teivainen PA, Eliassen KA, Rubin EM, Djurovic S, Berg K: Human apoB contributes to increased serum total apo(a) levels in LPA transgenic mice. Lipids in Health and Disease 2004, 3:8.

14. Neat CE, Thomassen MS, Osmundsen H: Effects of high-fat diets on hepatic fatty acid oxidation in the rat. Isolation of rat liver peroxisomes by vertical-rotor centrifugation by using a selfgenerated, iso-osmotic, percoll gradient. Biochemical Journal 1981, 196:149-159.

15. Thomassen MS, Christiansen EN, Norum KR: Characterization of the stimulatory effect of high-fat diets on peroxisomal betaoxidation in rat liver. Biochemical Journal 1982, 206:195-202.

16. Furnkranz A, Leitinger $\mathrm{N}$ : Regulation of inflammatory responses by oxidized phospholipids, structure-function relationships. Current Pharmaceutical Design 2004, 10:915-921.

17. Furnkranz A, Schober A, Bochkov VN, Bashtrykov P, Kronke G, Kadl A, Binder BR, Weber C, Leitinger N: Oxidized Phospholipids Trigger Atherogenic Inflammation in Murine Arteries. Arterioscler Thromb Vasc Biol 2005, 25:633-638.

18. Bergmark C: Oxidized Phospholipids and Lp(a) Lipoprotein, a role in Innate Immunity? "Genomics and Genetic Applications in Medicine" Symposium organized by S.K Thoresens foundation and The Norwegian Academy of Sciences, Oslo, May 19-May 2I, $2005: 44-46$. Abstract

19. Tadolini B, Cabrini I, Varani E, Sechi AM: Spermine binding and aggregation of vesicles of different phospholipid composition. Biogenic Amines 1985, 3:87-96.

20. CatrosQuemener V, Leray G, Moulinoux JP, Havouis R, deCertaines JD, Chapman J: Tumour growth modifies intravascular polyamine transport by plasma lipoproteins in the mouse. Biochimica et Biophysica Acta-Lipids and Lipid Metabolism 1997, 1346:30-37.

21. Navab M, Hama SY, Cooke CJ, Anantharamaiah GM, Chaddha M, Jin L, Subbanagounder G, Faull KF, Reddy ST, Miller NE, Fogelman AM: Normal high density lipoprotein inhibits three steps in the formation of mildly oxidized low density lipoprotein: step $I$. Journal of Lipid Research 2000, 4I: I 48I-1494.

22. Russell DH: Polyamines as biochemical markers of normal and malignant growth. Progress in cancer Research and Therapy 1973, 9:1-13.

23. Bergmeyer HU, Grassl M, Walter HE: Catalase. Verlag Chemie, Weinhein, Germany 1983, II: 165-167.

24. Hovik R, Osmundsen H: Peroxisomal beta-oxidation of longchain fatty acids possessing different extents of unsaturation. Biochemical Journal 1987, 247:531-535.

25. Hayashi $H$, Yoshida $H$, Hashimoto F, Okazeri S: Changes in polyamine-oxidizing capacity of peroxisomes under various physiological conditions in rats. Biochimica et Biophysica Acta 1989, $991: 310-316$. 
26. Okuyama T, Kobayashi Y: Determination of diamine oxidase activity by liquid scintillation counting. Archives of Biochemistry and Biophysics 1961, 95:242-250.

27. Smith TA, Best GR: Polyamines in barley seedlings. Phytochemistry 1977, 16:84I-843.

28. Seiler N, Wiechmann M: Microdetermination of spermine and spermidine as I-dimethylaminonaphthalene-5-sulfonic acid derivatives. Hoppe Seylers Z Physiol Chem 1967, 348:285-1290.

29. Seiler N, Knodgen B, Eisenbeiss F: Determination of di- and polyamines dimethylaminonaphthalene-I-sulfonyl derivatives. Journal of Chromatography 1978, 145:29-39.

30. Gornall AG, Bardawill CI, David MM: Determination of serum proteins by means of the biuret reaction. Journal of Biological Chemistry 1949, 177:751-766.

Publish with Bio Med Central and every scientist can read your work free of charge

"BioMed Central will be the most significant development for disseminating the results of biomedical research in our lifetime. "

Sir Paul Nurse, Cancer Research UK

Your research papers will be:

- available free of charge to the entire biomedical community

- peer reviewed and published immediately upon acceptance

- cited in PubMed and archived on PubMed Central

- yours - you keep the copyright

Submit your manuscript here:

http://www.biomedcentral.com/info/publishing_adv.asp
BiolMedcentral 